\title{
On Shear Testing of Single Crystal Ni-Base Superalloys
}

\author{
G. EGGELER, N. WIECZOREK, F. FOX, S. BERGLUND, D. BÜRGER, A. DLOUHY, \\ P. WOLLGRAMM, K. NEUKING, J. SCHREUER, L. AGUDO JÁCOME, S. GAO, \\ A. HARTMAIER, and G. LAPLANCHE
}

\begin{abstract}
Shear testing can contribute to a better understanding of the plastic deformation of Ni-base superalloy single crystals. In the present study, shear testing is discussed with special emphasis placed on its strengths and weaknesses. Key mechanical and microstructural results which were obtained for the high-temperature $\left(T \approx 1000{ }^{\circ} \mathrm{C}\right)$ and low-stress $(\tau \approx 200 \mathrm{MPa})$ creep regime are briefly reviewed. New 3D stereo STEM images of dislocation substructures which form during shear creep deformation in this regime are presented. It is then shown which new aspects need to be considered when performing double shear creep testing at lower temperatures $\left(T<800{ }^{\circ} \mathrm{C}\right)$ and higher stresses $(\tau>600 \mathrm{MPa})$. In this creep regime, the macroscopic crystallographic [11-2](111) shear system deforms significantly faster than the [01-1](111) system. This represents direct mechanical evidence for a new planar fault nucleation scenario, which was recently suggested (Wu et al. in Acta Mater 144:642-655, 2018). The double shear creep specimen geometry inspired a micro-mechanical in-situ shear test specimen. Moreover, the in-situ SEM shear specimen can be FIB micro-machined from prior dendritic and interdendritic regions. Dendritic regions, which have a lower $\gamma^{\prime}$ volume fraction, show a lower critical resolved shear stress.
\end{abstract}

https://doi.org/10.1007/s11661-018-4726-9

(C) The Author(s) 2018

\section{INTRODUCTION}

SINGLE crystalline Ni-base superalloys (SX) are used for first-stage blades of gas turbines which have to withstand mechanical loads up to very high temperatures. $^{[1,2]} \mathrm{SX}$ are heat-treated cast materials which represent technical single crystals, where the atoms of

G. EGGELER, N. WIECZOREK, F. FOX, S. BERGLUND, D. BÜRGER, P. WOLLGRAMM, K. NEUKING, and G. LAPLANCHE are with the Institut für Werkstoffe, RuhrUniversität Bochum, Universitätsstr. 150, 44801 Bochum, Germany and also with the Interdisciplinary Centre for Advanced Materials Simulation, Ruhr-Universität Bochum, Universitätsstr. 150, 44801 Bochum, Germany. Contact e-mail: gunther.eggeler@rub.de A. DLOUHY is with the Institute of Physics of Materials, ASCR, Zizkova 22, 61662 Brno, Czech Republic and also with the Interdisciplinary Centre for Advanced Materials Simulation, RuhrUniversität Bochum. J. SCHREUER is with the Institut für Geowissenschaften, Ruhr-Universität Bochum, Universittsstr. 150, 44801 Bochum, Germany and also with the Interdisciplinary Centre for Advanced Materials Simulation, Ruhr-Universität Bochum. L. AGUDO JÁCOME is with the Bundesanstalt für Materialforschung und -prüfung (BAM), Abteilung für Werkstofftechnik, Unter den Eichen 87, 12205 Berlin, Germany. S. GAO and A. HARTMAIER are with the Interdisciplinary Centre for Advanced Materials Simulation, Ruhr-Universität Bochum.

Manuscript submitted March 13, 2018.

Article published online June 13, 2018 two phases occupy one common crystal lattice. ${ }^{[1,2]}$ After processing, the microstructure consists of ordered cuboidal $\gamma^{\prime}$-particles $\left(\mathrm{Ll}_{2}\right.$-phase, volume fraction: $\approx 75$ pct, size: $\approx 500 \mathrm{~nm}$ ) which are separated by thin $\gamma$-channels (fcc-phase, volume fraction: $\approx 25$ pct, channel width: $\approx 100 \mathrm{~nm}$ ). In addition to this small-scale heterogeneity $\left(\gamma / \gamma^{\prime}\right.$-microstructure), one can distinguish between former dendritic (D) and interdendritic regions (ID), even after extended homogenization heat treatments (dendrite spacing: $\approx 400 \mu \mathrm{m}) \cdot{ }^{[3,4]}$ Most mechanical and microstructural results on yield strength and on creep of single crystal superalloys are obtained using uniaxial testing. Much less emphasis has been placed on shear loading.

Shear loading is attractive for three reasons. From a mechanical point of view, it represents a simple case of multiaxial loading (maximum principle stresses: $\sigma_{1}=$ $-\sigma_{3}, \sigma_{2}=0$ ). Thus, it can provide benchmark data for mechanical modellng. Shear testing moreover allows to directly load specific slip systems. Last but not least, it helps to study the effect of multiaxial and non-homogeneous stress states on rafting, the directional coarsening of the $\gamma^{\prime}$-phase under conditions of high-temperature and low-stress creep. The first part of this work takes a look at torsion and shear testing in general, and reviews and discusses some of the early work on SX shear testing. Then, we describe the double shear test 
technique which was developed by Mayr et al. ${ }^{[5]}$ A brief overview of the results obtained with this technique throughout the past two decades is given. We show how this technique has been used to study dislocation mechanisms and how it has contributed to a better understanding of high-temperature plasticity and rafting. In the second part of this article, we present new research results from the low-temperature and highstress creep regime. It is shown how this technique can help to understand processes which govern the nucleation of planar faults in the low-temperature and high-stress creep regime. Finally, it is shown that the size of the shear specimen proposed by Mayr et al ${ }^{[5]}$ can be scaled down by a factor of 1000 . The resulting micro-shear specimen can be used to perform in-situ SEM tests at room temperature, where one can differentiate between the mechanical properties of prior dendritic and interdendritic regions.

\section{SHEAR TESTING OF SUPERALLOY SINGLE CRYSTALS}

Shear strength of isotropic materials can be measured using shear and torsion tests which have been used in the materials and geo-science communities for a long time [e.g., References 6, 7]. Biaxial shear loading is often associated with torsion testing, where a cylindrical specimen is subjected to a torque parallel to its longitudinal axis. This forces the specimen to rotate. The twist which is caused in the specimen is known as torsion. For anisotropic Ni-base SX, torsion and tensile-torsion tests of thin-walled cylinders are useful as benchmark tests for macroscopic constitutive equations. ${ }^{[7-11]}$ However, these tests can result in inhomogeneous stress and strain distributions, as was discussed in the literature for conditions of elastic ${ }^{[7]}$ and elastoplastic material behavior. ${ }^{[8-11]}$ This is illustrated in Figure 1. At position $\mathrm{A}$ of the thin-walled cylinder shown in

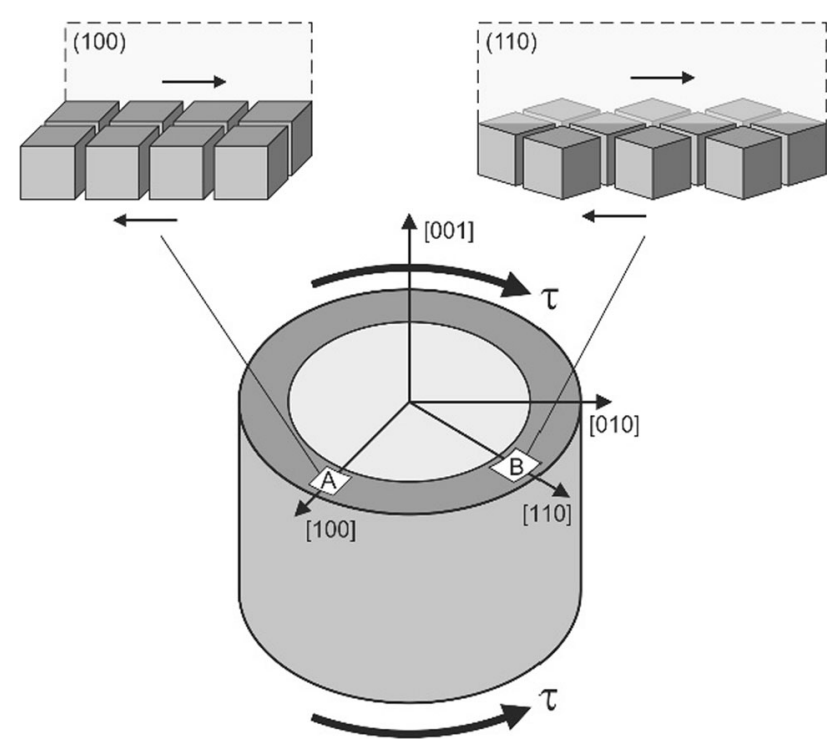

Fig. $1-$ On the difficulty to interpret results from torsion testing. For details see text.
Figure 1, shear occurs on (100) planes in $\pm[010]$ directions. At position B (at a circular distance of $\pi / 4$ from position A), planes of type (110) are subjected to shear in $\pm[-110]$ directions. Positions $A$ and $B$ differ in three respects. First, the elastic anisotropy of SX causes them to react differently to elastic loading. Second, different slip systems are activated during plastic deformation. Third, the spatial arrangement of the cuboidal $\gamma^{\prime}$-particles differs. During creep, these effects combine and make it difficult to interpret torsion creep data. Direct shear loading simplifies the situation. Different approaches for shear loading have been proposed in the literature, Figure 2. Figure 2(a) shows a simple shear test. $^{[12]}$ The test geometries shown in Figures 2(b) and (c) allow to create shear loading in tension and compression and were applied to SX. ${ }^{[13,14]}$ Figure 2(d) shows a double shear test which was used to study creep of metals for a long time. ${ }^{[15]}$ Figures 2(e) and (f) show how strong shear loading components can be and have been exploited in tensile loaded specimens. ${ }^{[16]}$ Double shear testing as schematically shown in Figure 2(d) was the most commonly used technique, ${ }^{[15,17-20]}$ probably because the symmetry of the specimen facilitates shear

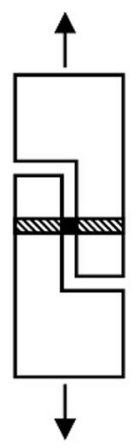

(a)

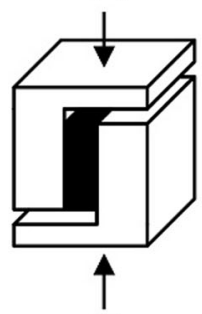

(c)

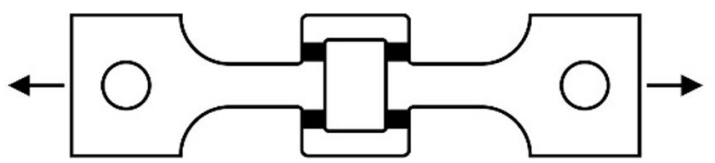

(e)

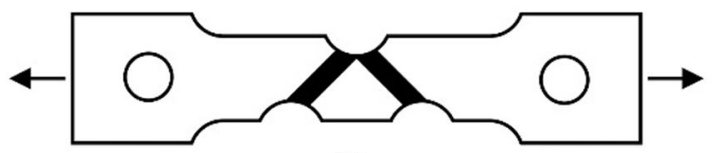

(f)

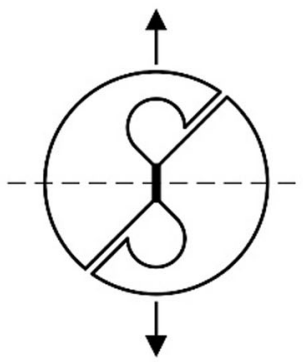

(b)

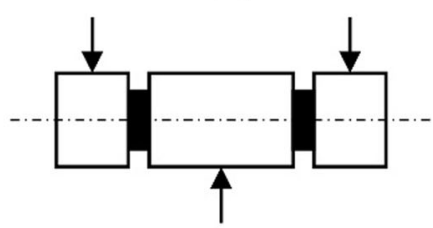

(d)
Fig. 2-Different ways to directly apply shear loads which were proposed in the literature. (a) Matsuda. ${ }^{[12]}$ (b) Funk and Blank. ${ }^{[13]}$ (c) Raoult-Rogez. ${ }^{[14]}(d)$ Schwartz et al. ${ }^{[15]}(e)$ and $(f)$ Touratier et al. ${ }^{[16]}$ 
loading. Mayr et al. ${ }^{[5]}$ applied double shear testing to superalloy single crystals. The difficulties encountered when designing a shear creep specimen are described in the following section.

\section{SHEAR TESTING AND THE MAYR DOUBLE SHEAR SPECIMEN}

When Mayr et al. ${ }^{[5]}$ started to work on shear creep testing, their objective was to use the double shear creep test ${ }^{[15]}$ to study creep of SX at temperatures above $1000{ }^{\circ} \mathrm{C}$. The technique should allow to directly load specific macroscopic crystallographic shear systems, like $\langle 1-10\rangle\{111\}$ or $\langle 100\rangle\{010\}$. It turned out that there were five experimental constraints which needed to be satisfied: (1) The shear specimen geometry should be small enough to allow specimens to be taken out in all required crystallographic orientations from typical laboratory cast SX pieces (like plates with thicknesses or cylindrical rods with diameters of $20 \mathrm{~mm}$ ). (2) The shear grips had to be designed together with the specimen. In uniaxial testing, the major parts of the tensile loading grips are located outside the hot zone of the furnace. In contrast, shear grips are fully exposed to the highest temperatures in the furnace and must not deform or fail. Stresses acting in the shear grips therefore have to be minimized. (3) The widths of the shear zones had to be large enough to allow for the accumulation of sufficient shear displacements, which could be transferred by rod in tube extensometry outside the furnace and easily measured. (4) The shear volumes should be large enough for taking out conventional 3-mm disk TEM samples from shear zone regions which deformed under a homogeneous shear stress state. (5) Superimposed bending, which cannot be avoided when applying shear loads, must be minimized. Mayr et al. ${ }^{[5]}$ based their design on mechanical analysis but also had to go through an extended trial and error period (not highlighted in Reference 5) to find a best compromise in view of these conflicting requirements. The resulting specimen geometry is shown in Figure 3(a).

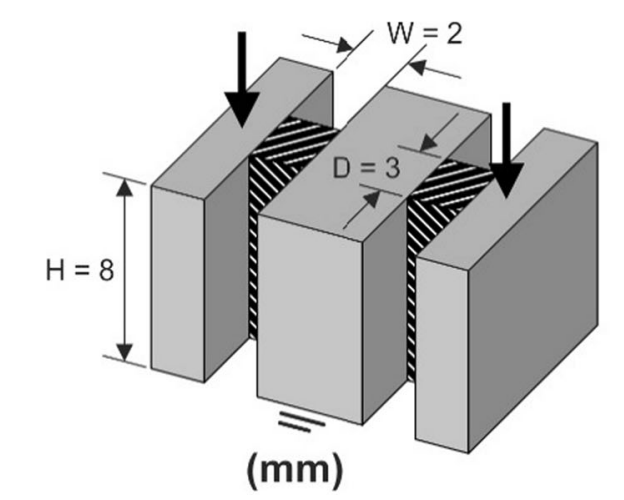

(a)
Shear specimens were machined using an iterative procedure involving orientation of the SX material in a Laue camera and spark erosion machining. The shear specimens can be oriented with an accuracy of \pm 2 deg. Sufficiently strong shear grips are made from the oxide dispersion strengthened material PM3030 from Plansee. A photograph of the shear grips is shown in Figure 9 of Reference 5. The shear grip assembly was machined such that the central loading part of the specimen shown in Figure 3 is pushed up while the two outer loading wings are pushed down. Shear strains $\gamma$ were measured by dividing the shear displacement $\Delta$ by the width $W$ of the shear zone:

$$
\gamma=\Delta / W
$$

Finite element (FEM) creep stress calculations were performed assuming isotropic material behavior and using a simple Norton creep law from the high-temperature and low-stress creep regime as a constitutive equation. ${ }^{[5,21]}$ These showed that under creep conditions, $80 \mathrm{pct}$ of the shear volumes were under a reasonably homogeneous shear stress state. Only the upper and lower 10 pct of the shear volumes were affected by superimposed bending stresses. In these outer zones, normal tensile (highest parts of shear zones) and compressive (lowest part of shear zones) stresses act perpendicular to the direction of shear loading. The FEM creep stress calculations also showed that valid shear creep tests can be performed up to shear strains of $\gamma=10$ pct, from where on the rotation of the outer loading wings becomes significant and alters the shear stress and strain states.

\section{EARLY MICROSTRUCTURAL AND MECHANICAL RESULTS}

Mayr et al. ${ }^{[5]}$ worked on CMSX-6, ${ }^{[5]}$ which was tested in the high-temperature $\left(1025^{\circ} \mathrm{C}\right)$ low-stress $(80 \mathrm{MPa})$ creep regime. They documented the test procedure and showed that their double shear creep test technique

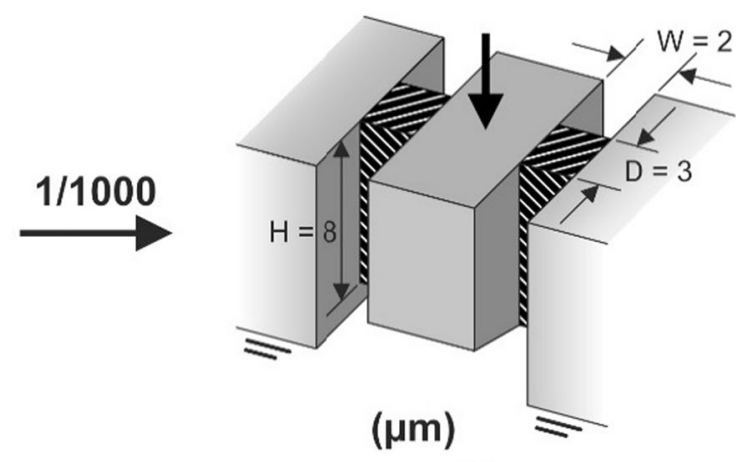

(b)

Fig. 3-Two geometric similar double shear specimens considered in the present work for testing superalloy single crystals. (a) Double shear creep specimen (mm-scale). (b) In-situ SEM micro double shear specimen ( $\mu \mathrm{m}$-scale). 
yielded reproducible shear creep data. They compared the creep behavior of two macroscopic shear systems, $\langle 1-10\rangle\{111\}$ and $\langle 100\rangle\{010\}$. Their creep curves showed no incubation periods and exhibited pronounced primary creep regimes where creep rates decreased by more than two orders of magnitude. Then, a secondary creep regime followed, where constant creep rates were observed over extended strain intervals. This secondary creep regime was reached after 4 pct shear strain for $\langle 1-10\rangle\{111\}$ loading where one slip system dominates in the early stages of creep (Schmid factors: one: 1.0, two: 0.67 , four: 0.50 , one: 0.33 , four: 0.17 ). For the case of the macroscopic shear system $\langle 100\rangle\{010\}$, the secondary creep regime was observed earlier, after 2 pct shear strain (Schmid factors: eight: 0.41, four: 0.00). Most importantly, it was found that in the secondary creep regime, the macroscopic crystallographic shear system $\langle 100\rangle\{010\}$ deformed by a factor of 10 slower than the $\langle 1-10\rangle\rangle\{111\}$ system. This presented clear proof for the fact that $\gamma$-channels do not simply represent soft regions which easily deform when subjected to shear loading in a $\gamma$-channel direction. While $\langle 1-10\rangle\rangle\{111\}$ shear creep loading promoted the dislocation family with the highest Schmid factor of 1 in the early stages of creep, other dislocation systems were also activated. It was not possible to activate single slip under conditions of high-temperature and low-stress creep. ${ }^{[22]}$ At the time, macroscopic cube slip was considered as an elementary deformation mechanism which is required to rationalize creep data using crystal plasticity approaches ${ }^{[23,24]}$ and it was claimed to play an important role during yield stress anomaly of $\mathrm{Ni}_{3} \mathrm{Al}^{\left[{ }^{[25]}\right.}$ This motivated the SX shear creep work, but no evidence for macroscopic cube slip was found after $\langle 100\rangle\{010\}$ shear creep testing of CMSX-6 at $1025^{\circ} \mathrm{C}$ and $80 \mathrm{MPa}$. Using conventional diffraction contrast transmission electron microscopy (TEM), a number of relevant microstructural observations were made after high-temperature and low-stress shear creep deformation. Thus, it was observed how dislocation networks form at $\gamma / \gamma^{\prime}$-interfaces. It was concluded that dislocations from different families need to enter the $\gamma$-channels to form networks and that climb processes are required to form regular networks. ${ }^{[5,22,26]}$ It was found that dislocation segments can move along $\gamma /$ $\gamma^{\prime}$-interfaces by a combined process of glide and climb. ${ }^{[26]}$ The formation of grooves at $\gamma / \gamma^{\prime}$-interfaces was documented and associated with a change of local chemical potential linked to the presence of dislocation stress fields. ${ }^{[26]}$ And it was also shown by diffraction contrast $^{[27]}$ and high-resolution TEM $^{[28]}$ that two $\gamma$-channel dislocations with different Burgers vectors can combine and shear the $\gamma^{\prime}$-phase, where they move by a combined motion of glide and climb. They form a superdislocation with an $\mathrm{a}_{0}\langle 100\rangle$ Burgers vector. The vacancies which are needed/provided by one dislocation are supplied/absorbed by the other. ${ }^{[27,28]}$ It has been pointed out that this represents part of a dynamic recovery process which must occur when the material creeps. ${ }^{[27-29]}$ It can be pointed out that this process has today been documented in different SX alloys (CMSX-6, ${ }^{[27,28,30]}$ NASAIR $100,{ }^{[29]}$ CMSX-4 ${ }^{[31,32]}$ ). Double shear creep testing has provided the deformed material states which allowed making the observations that are briefly described in this section and which are schematically summarized in Figure 4.

Most of these mechanisms have been or could have been identified in deformed material states after other types of thermomechanical treatments including uniaxial creep testing (e.g., formation of dislocation networks, ${ }^{[3-39]}$ grooves and ledges at interfaces of $\gamma /$ $\gamma^{\prime}$-microstructures ${ }^{[40-44]}$ or formation of $\langle 100\rangle$ dislocations in the $\gamma^{\prime}$-phase $\left.{ }^{[4,46]}\right)$. Shear creep testing still has advantages over uniaxial testing: One knows in which macroscopic crystallographic shear system plastic deformation takes place. The primary creep range extends over a large strain interval. Moreover, in the secondary creep regime, one obtains constant creep rates over large strain intervals. There were two microstructural results which could not have been easily obtained using uniaxial creep testing. Carrol et al. ${ }^{[47]}$ showed that the measured creep rate in double shear samples following a load reversal is considerably higher than the initial forward creep rate. Carroll et al. ${ }^{[47]}$ observed this for other materials too, but not to the extent seen in the Ni-base superalloy CMSX-4. A basis for this jump in reverse creep rate is grounded in the principle by which dislocations fill the $\gamma$-channels in the early stages of creep.

As is schematically illustrated in Figure 5(a), during forward creep, a leading screw segment glides through the $\gamma$-channel, where it deposits sessile $60 \mathrm{deg}$ dislocations in the $\gamma / \gamma^{\prime}$-interfaces. These are free to move away from the interfaces when the load is reversed, Figure 5(b).

High-temperature low-stress shear creep experiments have also contributed to a better understanding of rafting. ${ }^{[48]}$ First, it could be shown that, in a shear test which is performed in the macroscopic $\langle 100\rangle\{010\}$ shear system, the microstructure sensitively reacts to the small superimposed tensile and compressive bending stresses in the outer parts of the shear zones. One can observe rafting perpendicular and parallel to the direction of macroscopic shear loading, as schematically indicated in Figure 5(c) by small parallel black lines which indicate the direction of rafts. In the center of the shear zones of a $\langle 1-10\rangle\{111\}$ shear test, one finds that rafts form at an angle of $45 \mathrm{deg}$ to the direction of the applied shear load. In fact, during $\langle 1-10\rangle\{111\}$ shear creep deformation, rafts form perpendicular to the direction of the maximum principal stress (shear loading: $\sigma_{1}=-\sigma_{3}$, $\sigma_{2}=0$ ) as schematically illustrated in Figure 5(d) (pairs of parallel black lines indicating the orientation of rafts in the major part of the shear zone). Serin et al. ${ }^{[49]}$ compared double shear and tensile experiments at the same values of maximum principal stress. They found similar rafting kinetics and concluded that in the presence of a multiaxial stress state, the kinetics of rafting is governed by the maximum principal stress $\sigma_{1}$. 


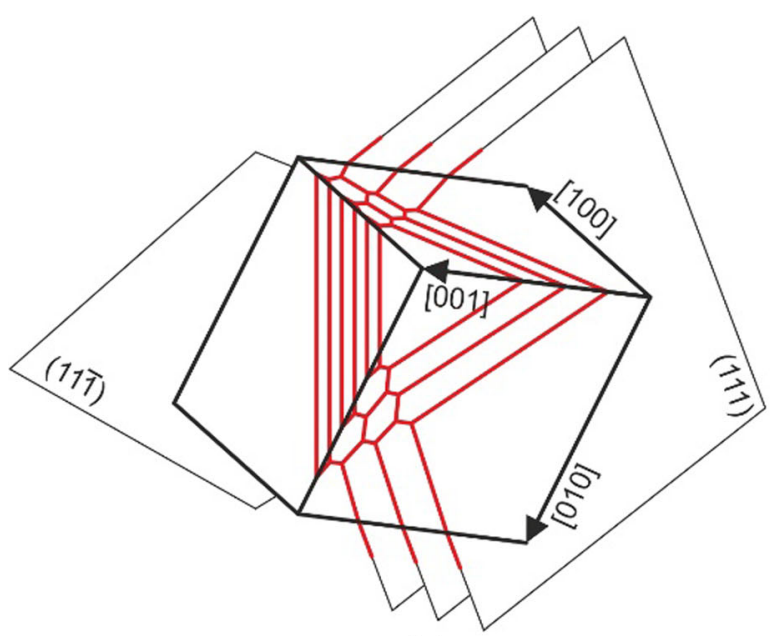

(a)

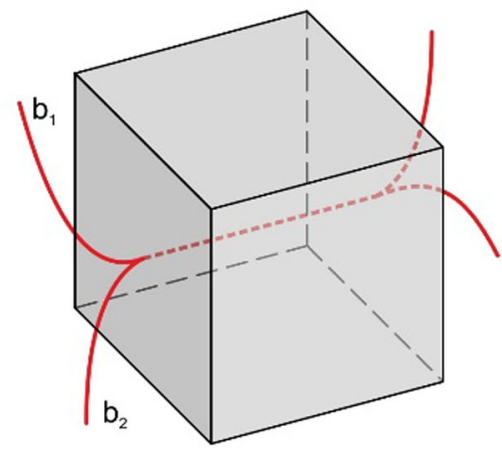

(c)

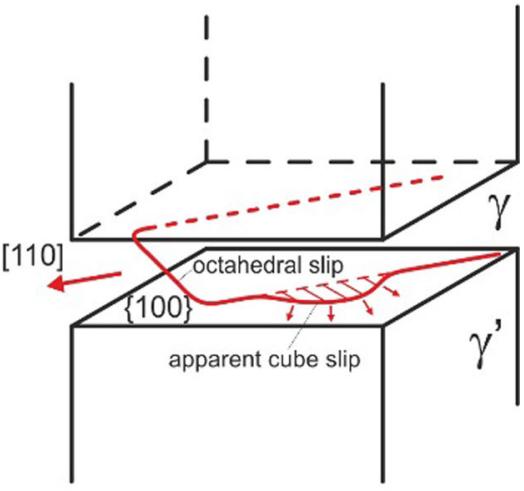

(b)

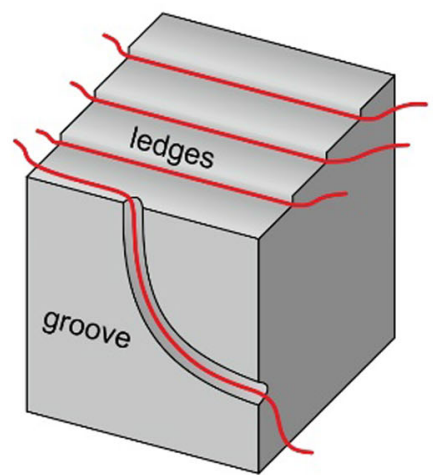

(d)

Fig. 4 - Schematic illustrations of processes which were observed after double shear creep testing of superalloy SX in the high-temperature and low-stress creep regime. (a) Formation of dislocation networks at interfaces. ${ }^{[22,26]}(b)$ Glide and climb movement of an ordinary $a_{0} / 2\langle 110\rangle\{111\}$ dislocation in $\gamma$-channels along a $\gamma / \gamma^{\prime}$-interface. ${ }^{[26]}(c)\langle 100\rangle$ dislocations in the $\gamma^{\prime}$-phase formed from two ordinary $\gamma$-channel dislocations (with different Burgers vectors) which move in a combined motion of glide and climb. ${ }^{[27,28]}$ (d) Dislocations form ledges and grooves at $\gamma /$ $\gamma^{\prime}$-interfaces. ${ }^{[26]}$

\section{HIGH-TEMPERATURE AND LOW-STRESS SHEAR CREEP DATA}

Kamaraj et al. ${ }^{[50]}$ published a set of double shear creep data for CMSX-4 for the high-temperature low-stress creep regime. Double shear creep testing was performed at temperatures ranging from $950{ }^{\circ} \mathrm{C}$ to $1100{ }^{\circ} \mathrm{C}$ at shear stresses between 80 and $155 \mathrm{MPa}$. Four macroscopic crystallographic shear systems were considered, which are schematically illustrated in Figure 6(a). Creep data which were recorded at $950{ }^{\circ} \mathrm{C}$ and $1050{ }^{\circ} \mathrm{C}$ are shown in Figure 6(b), where the logarithm of shear rate is plotted as a function of shear strain. The tests performed at $1050{ }^{\circ} \mathrm{C}$ fall in a narrow scatter band. The $\langle 01-1\rangle\{111\}$ shear system (highest average of the absolute values of Schmid factors of 0.45 ) deforms fastest, while the $\langle 100\rangle\{010\}$ system deforms slowest (lowest average of the absolute values of Schmid factors of 0.27). When the temperature is lowered to $950{ }^{\circ} \mathrm{C}$, the crystallographic scatter band widens. Again, the macroscopic $\langle 1-10\rangle\{111\}$ system creeps fastest while the $\langle 100\rangle\{010\}$ system deforms slowest. The data presented in Figure 6(b) allow to conclude that in the high-temperature and low-stress creep regime, where climb processes are important, there is an influence of crystallographic loading direction on creep. This scales with the average value of the absolute Schmid factors of the 12 associated octahedral slip systems. However, the influence of crystallography is not very strong.

Kamaraj et al. ${ }^{[50]}$ measured shear creep rates after accumulated strains of 3 pct and represented the data by a law of type:

$$
\dot{\gamma}_{3 \mathrm{pct}}=c \cdot \tau^{n} \cdot \exp \left(-\frac{Q_{\mathrm{app}}}{R \cdot T}\right),
$$

where $\dot{\gamma}_{3 \text { pct }}$ is the shear creep rate measured after 3 pct creep strain, c is a constant, $\tau$ is the shear stress, $n$ is the Norton stress exponent, $Q_{\mathrm{app}}$ is the apparent activation energy of creep, and $R$ and $T$ are the gas constant and the absolute temperature. The corresponding Norton and Arrhenius plots of the four shear systems are plotted in Figures 6(c) and (d). The slopes of the lines that limit the gray scatter fields in Figures 6(c) and (d) correspond to $n$ and $Q_{\text {app }}$ values of 6 and $500 \mathrm{~kJ} / \mathrm{mole}$, respectively. These values lie inside the range of literature data which have recently been reviewed by Wollgramm et al. ${ }^{[51]}$ The first research period of shear 


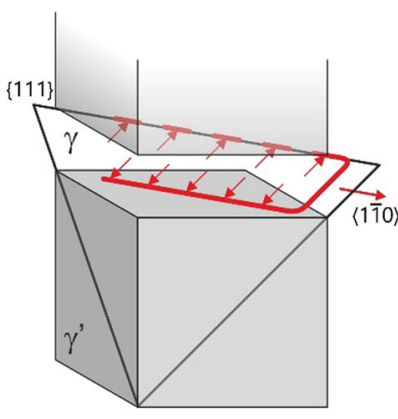

(a)

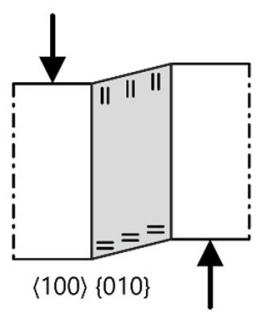

(c)

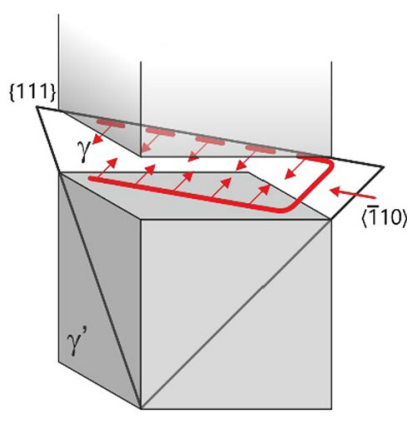

(b)

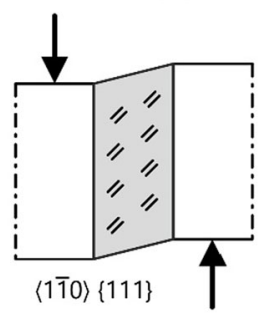

(d)
Fig. 5-Schematic illustration of microstructural processes which occur during shear loading of single crystal superalloys. (a) Dislocations enter channels and deposit long interface dislocation segments. $^{[47]}$ (b) Dislocations from both $\gamma / \gamma^{\prime}$-interfaces from one $\gamma$-channel approach each other on load reversal. ${ }^{[47]}(c)$ Rafting reacts to superimposed bending stresses in the outer parts of the shear zones during $\langle 100\rangle\{010\}$ shear testing. ${ }^{[48]}$ (d) Rafts form at 45 deg to the shear loading direction during $\langle 1-10\rangle\{111\}$ shear creep testing. ${ }^{[48]}$

creep testing ended with a short overview summary given in $2009,{ }^{[52]}$ which focused on the rafting aspects reported in the previous section.

\section{NEW RESULTS ON SHEAR TESTING OF NI-BASE SUPERALLOY SINGLE CRYSTALS}

Recently, shear testing of Ni-base superalloys has received new attention. It is one of the key mechanical test techniques which are used by researchers from the collaborative research center SFB/TR 103 funded by the Deutsche Forschungsgemeinschaft. ${ }^{[53]}$ Most of the work is still ongoing but there are some new results on shear testing of single crystal superalloy, which are reported in this section.

\section{A. Spatial Arrangement of Dislocation Substructures After Creep}

Agudo Jácome et al. ${ }^{[54]}$ investigated the shear creep deformation of the single crystal superalloy LEK 94 in the macroscopic crystallographic shear system $[01-1](011)$ at temperatures between $980{ }^{\circ} \mathrm{C}$ and $1050{ }^{\circ} \mathrm{C}$ and shear stresses between 50 and $140 \mathrm{MPa}$. They described the shape of the creep curves and determined a stress exponent and an apparent activation energy from secondary creep rate data as $n=6$ and $Q_{\text {app }}=466 \mathrm{~kJ} / \mathrm{mol}$. They suggested to modify the Larson-Miller parameter for comparing data from tests which were performed at different temperatures. They could confirm that uniaxial and shear creep testing in the high-temperature and low-stress creep regime are governed by similar dislocation processes. Most importantly, cutting of $\gamma^{\prime}$-particles was observed and superdislocations with Burgers vectors of $a 220$ and a200 were identified. Here, new 3D STEM images (anaglyphs) are presented. They were produced following the procedure outlined in Reference 55.

The micrographs were taken at a magnification that allows to appreciate dislocation activities in the $\gamma$-channels and in the $\gamma^{\prime}$-phase. Under the experimental conditions considered, the $\gamma^{\prime}$-particles have already rafted. It is easy to distinguish the $\gamma^{\prime}$-phase because it contains a lower number of dislocations. Dislocation networks are observed in the $\gamma$-channels. The three 3D images show that, when the temperature is raised at a constant stress (comparison upper left and upper right image), the widths of the $\gamma$-channels increase and dislocations seem to be able to move more easily. When, on the other hand, the stress is raised at this higher temperature (comparison upper right with lower right image), then the dislocation density in both phases increases. For a quantitative evaluation of the microstructural parameters of the material states shown in Figure 7, see Reference 54.

\section{B. Anisotropic Creep Stress Calculations}

As has been pointed out in the section on shear specimen design, it is not possible to create a pure shear stress state. Bending always is superimposed, which needs to be minimized. Finite element creep stress analysis helps to describe the homogeneity of the shear stress state. In previous work, ${ }^{[5,21]}$ finite element creep stress and strain calculations were performed for the high-temperature and low-stress creep regime, where creep anisotropy is not very strong. A simple Norton type of creep law was used and isotropic material behavior was assumed. It is well known that crystallographic orientation has a much stronger effect on creep at lower temperatures and higher stresses [e.g., Reference 56]. Therefore, in the low-temperature high-stress regime, it is not sufficient to assume homogeneous material behavior and to ignore primary creep. Gao et al. ${ }^{[57]}$ have recently developed an anisotropic constitutive model for creep of single crystal Ni-base superalloys in the low-temperature and high-stress creep regime. They used uniaxial creep data for the Ni-base single crystal superalloy ERBO $1 \mathrm{C},{ }^{[3]}$ published by Wollgramm et al. ${ }^{[58]}$ for $\langle 100\rangle$-, $\langle 110\rangle$-, and $\langle 111\rangle$-tensile directions, to tune the parameters of the coupled set of differential equations in their model. ${ }^{[57]}$ For the present work, this model was implemented into a user-defined subroutine UMAT of the FEM software package ABAQUS 6.11. As can be seen in Figure 8, a full double shear creep specimen is modeled using 3584 C3D8 elements (eight integration points per element), which are compatible with our UMAT and yield accurate results. Prior to the FEM calculations, the mesh size was refined until no more changes occurred. The resulting mesh size can be seen in Figure 8. This 


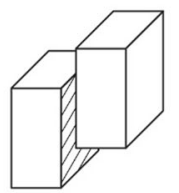

$\langle 110\rangle\{001\}$

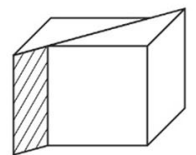

$\langle 01 \overline{1}\rangle\{011\}$
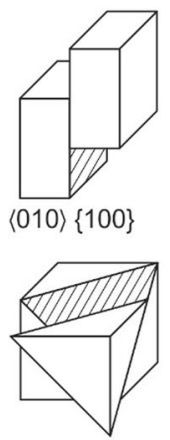

$\langle 01 \overline{1}\rangle\{111\}$

(a)

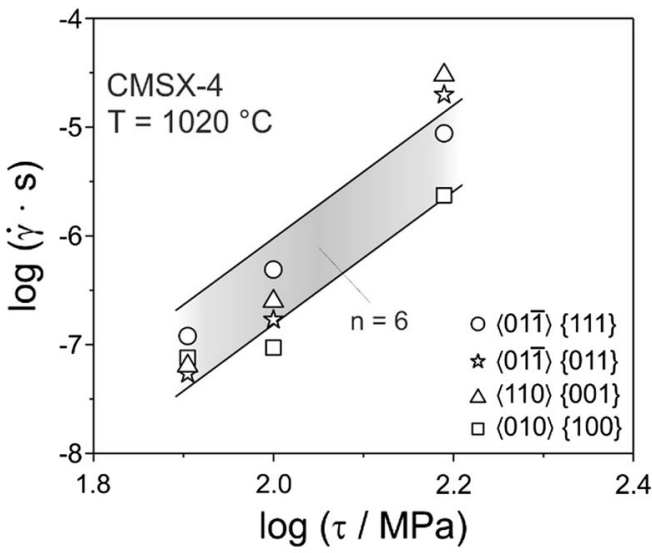

(c)

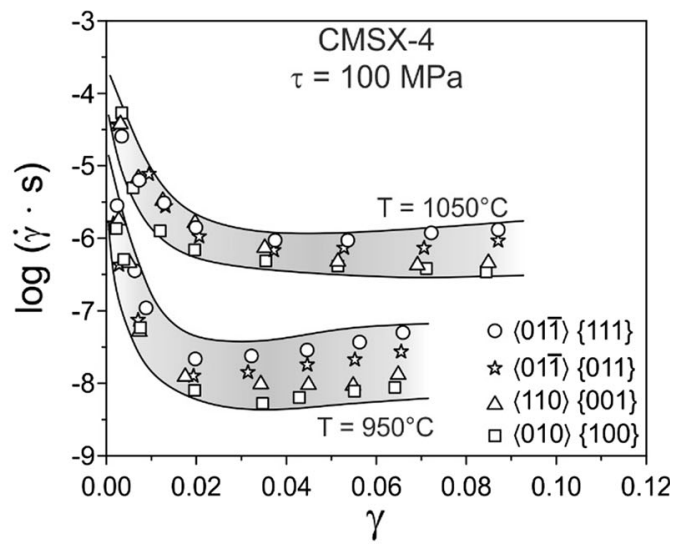

(b)

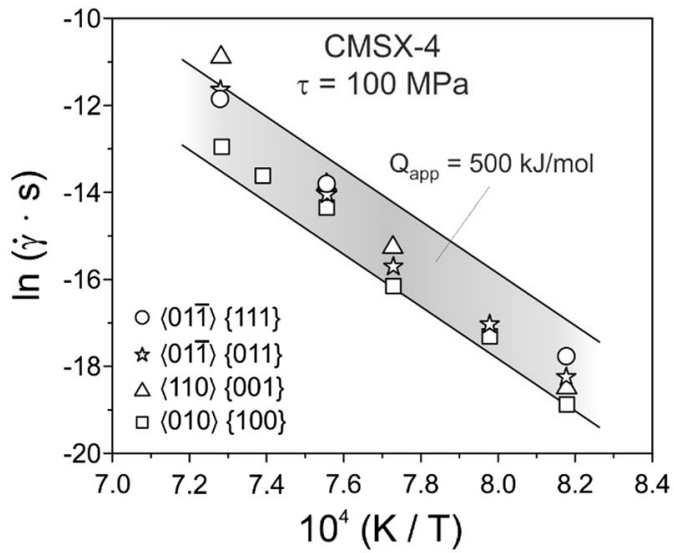

(d)

Fig. 6- Overview summary of double shear creep data reported for CMSX-4. ${ }^{[50]}$ (a) Schematic illustration of macroscopic crystallographic shear systems which were investigated. (b) Logarithmic shear creep rate data as a function of shear strain for the four macroscopic crystallographic shear systems from (a). (c) Stress dependence of secondary creep rate data at $1020{ }^{\circ} \mathrm{C}$ (Norton plot; scatter band slope: $n=6$ ). (d) Temperature dependence of secondary creep rate data at $100 \mathrm{MPa}$ (Arrhenius plot; $Q_{\text {app }}$ from slope: $-\mathrm{Q} / R$; scatter band slope: $Q_{\text {app }}=500 \mathrm{~kJ} / \mathrm{mole}$ ).

mesh size represents an excellent compromise between high accuracy and not too long computation time. As can be seen in Figure 8, loading was performed by fixing the bottom part of the central loading grip and by applying a surface pressure load of $262 \mathrm{MPa}$ on both top parts of the two outer loading wings (indicated as small black arrows P in Figure 8). During shear creep deformation, the top surfaces of the outer loading wings were forced to stay horizontal and were only allowed to move in negative $z$-direction. Loading was performed in two steps. First, the specimen was elastically loaded within 1 second. Then creep was allowed to start. A maximum time step duration of 100 seconds was fixed, but ABAQUS uses smaller time steps which it adjusts automatically using in-built convergence procedures. The simulations can be taken through to high strains; however, they were interrupted after 5 pct, where lattice rotations are negligible.

This type of loading results in a net section shear stress of $300 \mathrm{MPa}$ in both shear zones, which is constant throughout the creep FEM simulation. Figure 9 shows the distribution of the shear stress denoted as $S_{13}$ in the specimen after 100 hours of shear creep loading.
Figure 9(a) presents the shear stress distribution in the whole double shear specimen. Note that the shear directions in both shear zones differ, resulting in positive (red) and negative (blue) shear stress values. Figures 9(b) through (d) show 3D images obtained from different cuts through the double shear creep specimen. In Figures 9(b) and (c), the double shear creep specimen was cut perpendicular to the shear plane. Figure 9(d) shows a view onto an outer loading wing together with half of the connected shear zone. It is clear from Figure 9 that, even when an anisotropic creep law is used to describe stresses and strains in the double shear creep specimen, the majority of the two shear volumes $(80 \mathrm{pct})$ is under a homogeneous shear stress state close to $300 \mathrm{MPa}$. It can also be seen that the stresses which act in the outer loading wings and in the central loading part of the double shear creep specimen are low. The results presented in Figure 9 show that the shear stress distribution in the low-temperature and high-stress creep regime calculated with an anisotropic constitutive equation is similar to that, which is obtained when assuming isotropic material behavior and using a simple Norton law. ${ }^{[5,21]}$ This result appears reasonable because 

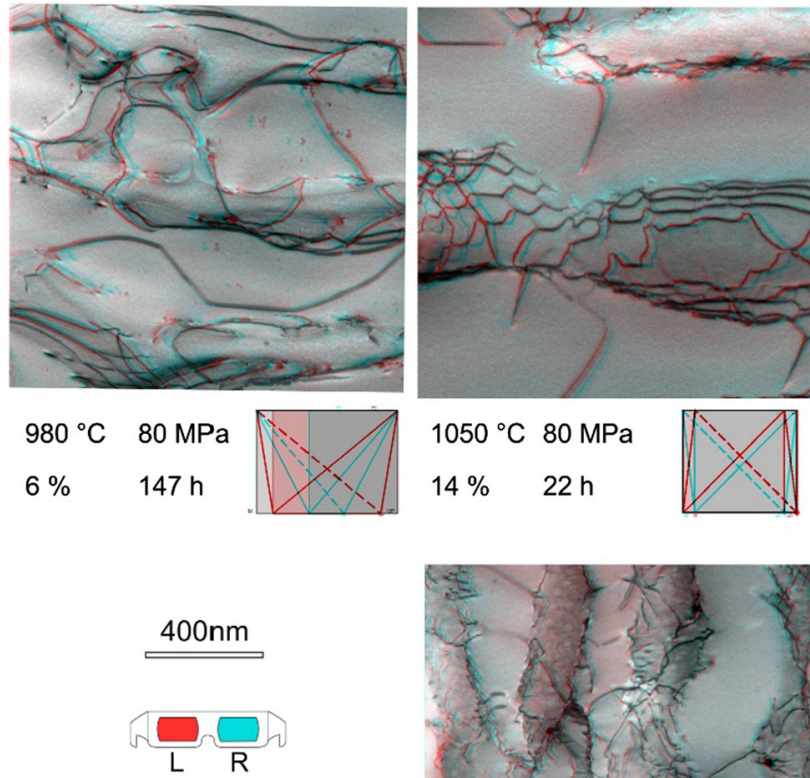

TEM anaglyphs (Agudo et al. 2015)

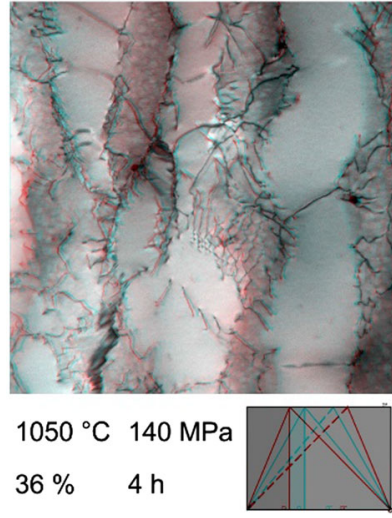

Fig. 7-3D TEM anaglyphs which were obtained using the procedure outlined in Ref. [55] after shear creep testing of the macroscopic crystallographic shear system $[01-1](011)$ at the conditions indicated. All three images were taken at the same magnification. Viewing the image with colored glasses (left eye: red glass, right eye: cyan glass) allows the viewer to appreciate the spatial arrangement of all microstructural features.

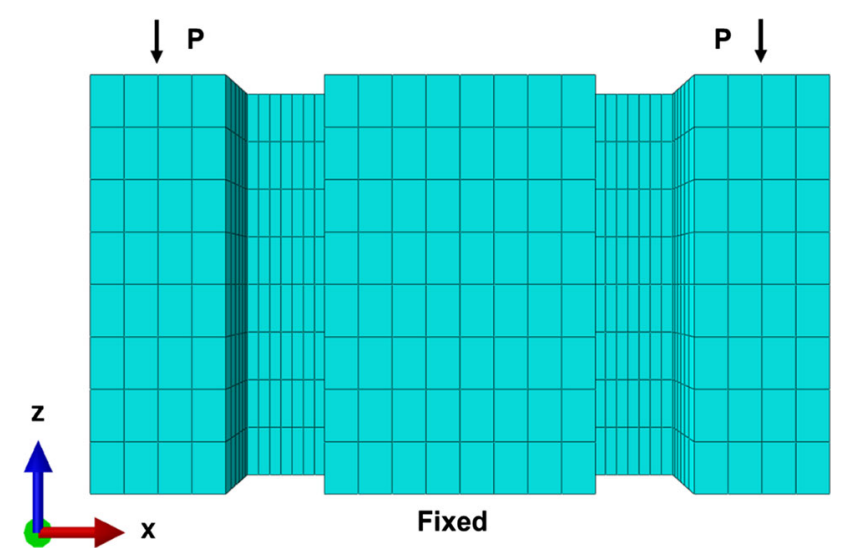

Fig. 8-Finite element model of the double shear creep specimen showing the mesh size, illustrating the loading procedure and defining the axis of the Cartesian co-ordinate system $(x=1$, red arrow pointing to the right; $y=2$, green arrow pointing into the image plane; $z=3$, blue arrow pointing up). For details see text.

the stress relaxation/redistribution during the viscoplastic deformation rapidly homogenizes the stress field heterogeneities inherited at the end of the initial elastic loading.

\section{Shear Creep Anisotropy in the Low-Temperature and High-Stress Creep Regime}

Figure 10 shows shear creep curves for the single crystal superalloy ERBO $1 \mathrm{C}^{[3]}$ from the low-temperature high-stress creep regime. The shear stress of $300 \mathrm{MPa}$ was chosen in order to have similar loading conditions on the activated slip systems as during $\langle 100\rangle$ tensile creep testing under $800 \mathrm{MPa}$ (resolved shear stress: $326 \mathrm{MPa}$ ). Four creep curves are shown in Figure 9, plotted as shear strain $\gamma v s$ time $t$. Two experiments were performed for the macroscopic crystallographic shear system [01-1](111). Another two shear tests were performed for the $[11-2](111)$ macroscopic crystallographic shear system. The tests shown in Figure 10 were interrupted after 5 pct shear strain. Figure 10 shows that the shear tests yield reproducible results. Most importantly, the [11-2](111) shear specimens deform significantly faster than the $[01-1](111)$ shear specimens. This seems surprising, because the average Schmid factor from the 12 octahedral slip systems in the macroscopic crystallographic shear system $[01-1](111)$ is high (average value: 0.445). Moreover, this shear system has the most highly loaded microscopic crystallographic slip system with a Schmid factor of 1. The macroscopic shear system [11-2](111) has a lower average Schmid factor of 0.417. The two most highly loaded microscopic crystallographic slip systems have both Schmid factors of 0.87 .

Recent TEM analysis and micro-mechanical modeling have shown that these two microscopic crystallographic slip systems must react in the $\gamma$-channels in order to nucleate a $\langle 112\rangle$ dislocation ribbon in the $\gamma^{\prime}$-phase. ${ }^{[59]}$ This reaction is promoted during [11-2](111) shear creep testing, where two partner dislocation families react and initiate the 1/3[11-2](111) planar slip in the $\gamma^{\prime}$-phase with higher probability.

Two additional creep experiments (creep curves not shown) were performed under the creep conditions highlighted in Figure $10\left(750{ }^{\circ} \mathrm{C}, 300 \mathrm{MPa}\right)$, one for each crystallographic shear system. The two tests were interrupted after 1 pct shear. The resulting material states were investigated using transmission electron microscopy (TEM). For this purpose, thin disks were cut out parallel to the shear planes. Thin electron transparent foils were prepared from these disks using double-jet thinning as described in Reference 59. The foils were positioned in a double-tilt TEM holder such that the holder axis was parallel to the shear directions. Scanning Transmission Electron Microscopy (STEM) was performed using a TEM of type JEM 2100 from Jeol. The corresponding two bright-field (BF) STEM micrographs, which were taken using a two-beam condition of $g=(-1-11)$ are shown in Figure 11. Figure 11(a) shows the dislocation substructure after 1 pct shear creep deformation of the [01-1](111) system. In Figure 11(a), dislocation segments with Burgers vectors of type $1 / 2\langle 01-1\rangle$ are deposited at $\gamma / \gamma^{\prime}$-phase interfaces while no $1 / 3\langle 11-2\rangle$ cutting events are observed. In contrast, six (highlighted by white dots) are found in Figure 11(b). The mechanical and microstructural results presented in Figures 10 and 11 

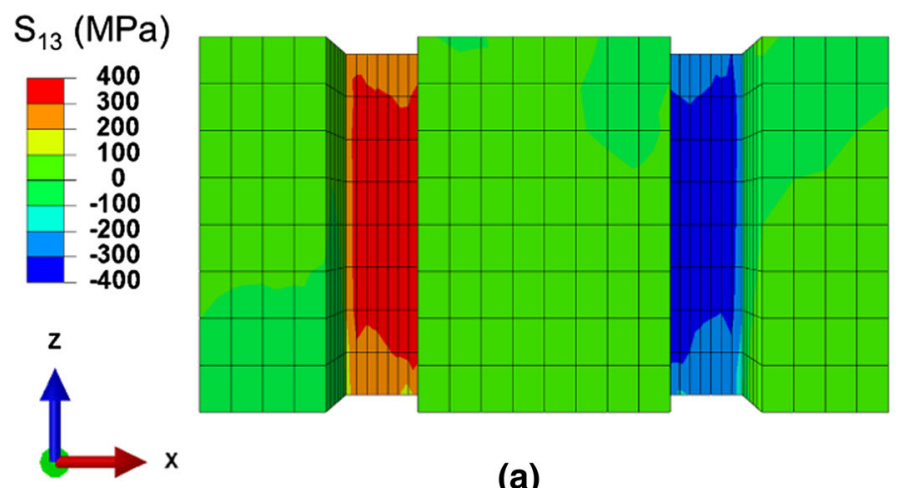

(a)

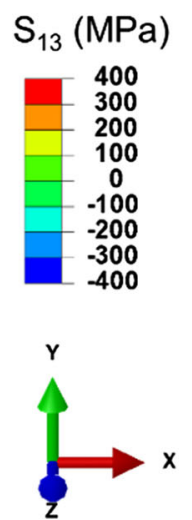

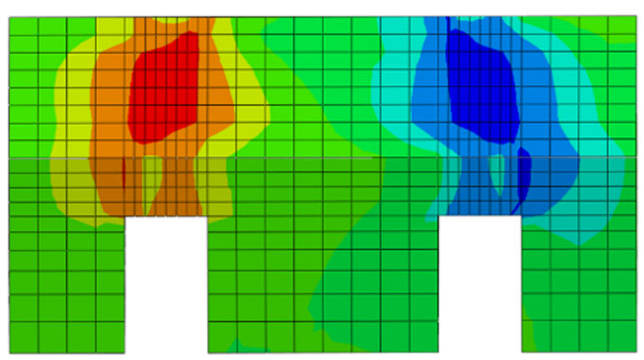

(c)
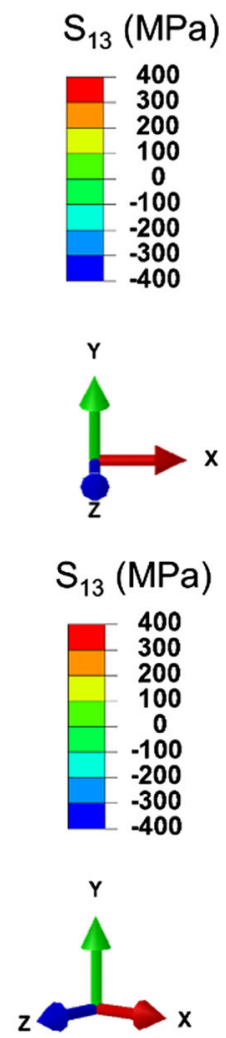

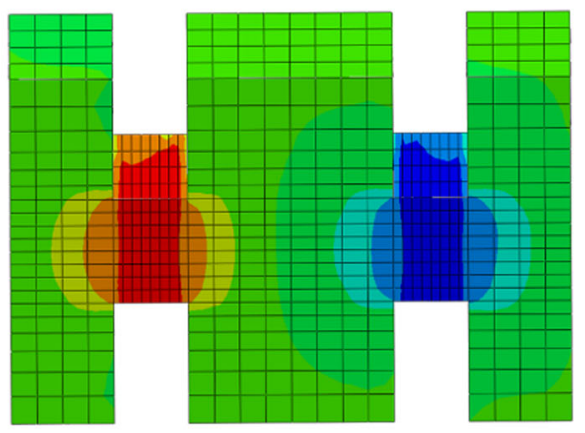

(b)

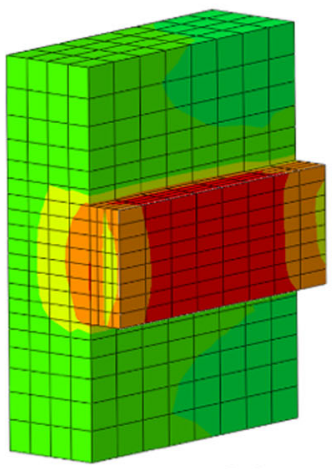

(d)

Fig. 9-Finite element creep stress results for the distribution of the shear stress $\left(S_{13}\right)$ in the shear specimen shown in Figure 3(a). (a) Full view of specimen ( $x$-axis " 1 " perpendicular to shear plane, $z$-axis " 3 " parallel to the shear direction). (b) 3D view of shear stress distribution in specimen cut in the center, normal to the $y$-axis and rotated around the $x$-axis. (c) Lower part of shear specimen shown in Figure 8(b). (d) 3D view of shear stress distribution in outer loading wing and in the connected part of the shear zone.

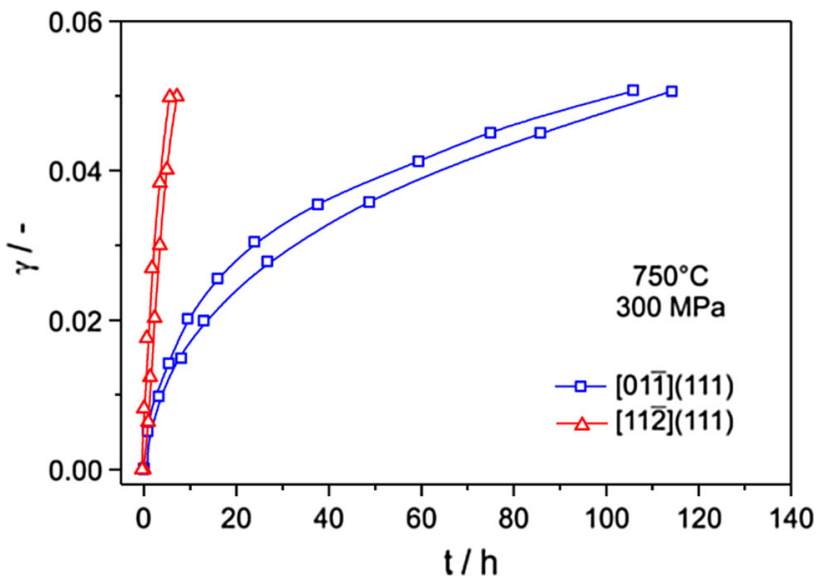

Fig. 10 - Creep curves plotted as shear strain $\gamma$ as a function of time t. Creep conditions: $750{ }^{\circ} \mathrm{C}, 300 \mathrm{MPa}$, termination of experiment: 5 pct strain. The $[11-2](111)$ shear system deforms significantly faster than $[01-1](111)$.

provide clear evidence for the fact that when the two dislocation families which are required to nucleate a $\langle 112\rangle$ dislocation ribbon are driven by similarly high Schmid factors, then the corresponding shear system creeps faster because $\langle 112\rangle$ ribbons form easier. The results presented in Figures 10 and 11 provide mechanical and microstructural proof for the importance of $\langle 112\rangle$ cutting of the $\gamma^{\prime}$-phase and contribute to a better understanding of low-temperature and high-stress creep of single crystal Ni-base superalloys. ${ }^{[58-60]}$ Further TEM studies are required to confirm these observations by investigating larger TEM foil regions and by analyzing the dislocation substructures in detail.

\section{In-situ SEM Micro-shear Testing of Single Crystal Ni-Base Superalloys}

Finally, an attempt is made to investigate the Ni-base superalloy single crystal ERBO-1 ${ }^{[3]}$ using in-situ $\langle 1-10\rangle\{111\}$ SEM micro-shear testing. The objective is to explore whether the small differences in $\gamma^{\prime}$-volume fractions between dendritic (D, lower: $72 \mathrm{pct}$ ) and interdendritic regions (ID, higher: $77 \mathrm{pct}$ ) reported earlier ${ }^{[3,4]}$ manifests itself in a difference in critical resolved shear stresses (CRSS) and whether large-scale microstructural heterogeneities manifest themselves during microshear testing. For this purpose, the micro double shear specimen shown in Figure 3(b) was derived from the macro double shear creep specimen shown in Figure 3(a). The shear zones of this in-situ micro-shear specimen are 1000 times smaller than in case of the original double shear creep specimen, Figure 3. This micro-shear specimen geometry was successfully used to test annealed $\mathrm{Au}$ single crystals ${ }^{[61]}$ and strain-hardened 

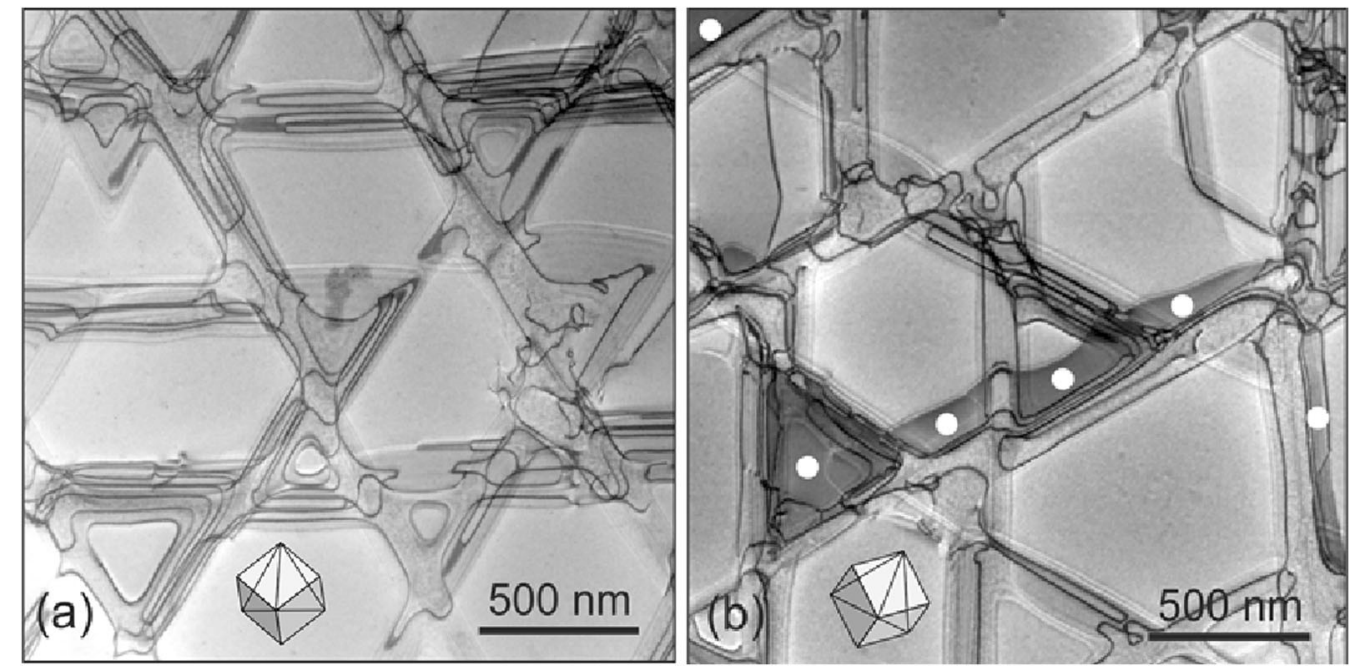

Fig. 11-STEM images from materials states which were deformed at $750{ }^{\circ} \mathrm{C}$ and $300 \mathrm{MPa}$ to 1 pct shear strain. The images were taken using a $\boldsymbol{g}=(-1-11)$ two-beam condition. (a) [01-1](111) shear system (one octahedral dislocation family has a Schmid factor of 1). No planar faults are observed. (b) [11-2](111) shear system (the two dislocation families which are required to form a $\langle 112\rangle$ dislocation ribbon have Schmid factors of 0.87 . Six planar faults are highlighted by white dots.
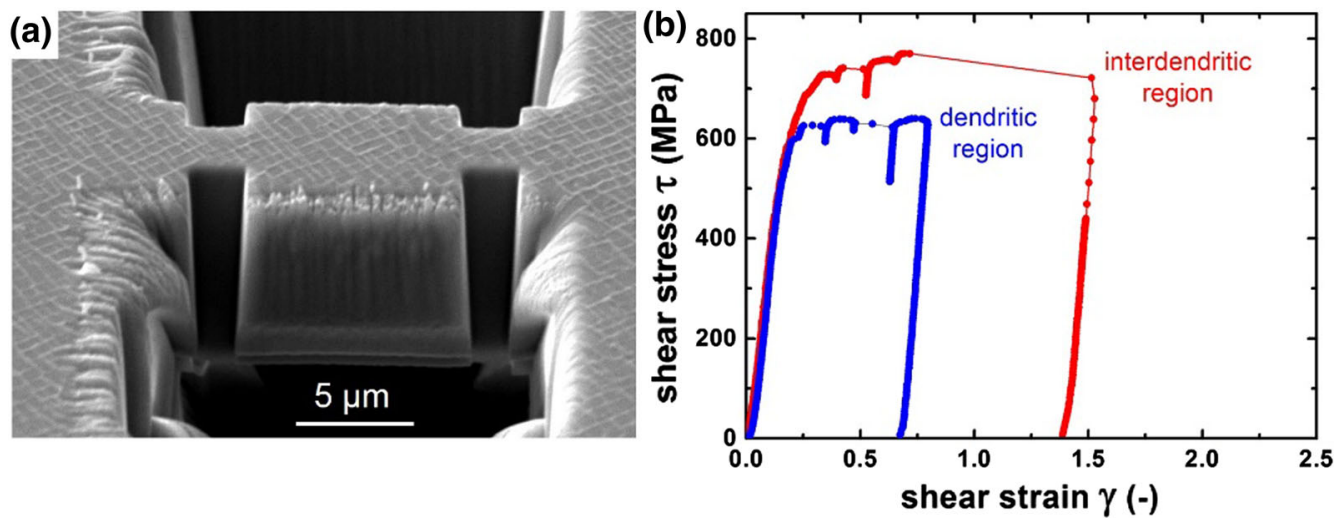

Fig. 12-In-situ micro-shear testing of a Ni-base single crystal superalloy. (a) FIB micro-machined SX in-situ SEM micro-shear specimen (specimen preparation and test details in Refs. $[62,63])$. (b) Dendritic regions with lower $\gamma^{\prime}$ volume fractions $\left(72\right.$ pet $\left.{ }^{[3,4]}\right)$ show lower yield stresses than interdendritic regions with higher $\gamma^{\prime}$ volume fractions $\left(77 \mathrm{pct}^{[3,4]}\right)$.

$\mathrm{Cu}$ single crystals. ${ }^{[62]}$ An in-situ micro double shear SX specimen after focused ion beam micro-machining and prior to room temperature shear testing in the SEM is shown in Figure 12(a).

The specimen is oriented for single slip, i.e., the shear plane and the loading direction are parallel to the (111)-plane and the [01-1]-direction, respectively. The $\gamma / \gamma^{\prime}$-microstructure is clearly visible (bright $\gamma$-channels, darker $\gamma^{\prime}$-particles). Figure 12(b) shows that the in-situ micro-shear test can indeed pick up the differences between regions with lower (dendritic regions) and higher $\gamma^{\prime}$-volume fractions (interdendritic regions). The fact that a higher $\gamma^{\prime}$-volume fraction yields a higher yield stress is in line with what one would expect. ${ }^{[63]}$ The result that there are mechanical differences between dendritic and interdendritic regions is in line with previous results from Tromas et al. ${ }^{[64]}$ who investigated a single crystal superalloy using nanoindentation. A statistical interpretation of their data showed that there are mechanical differences between dendritic and

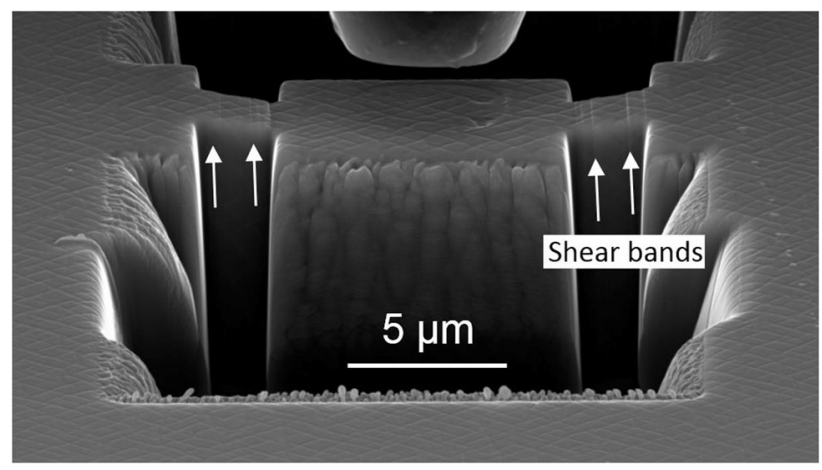

Fig. 13-Evidence for the formation of localized shear bands in the shear zones recorded during $\langle 1-1-0\rangle\{111\}$ in-situ SEM micro-shear testing of superalloy single crystals.

interdendritic regions. In their alloys of type $\mathrm{MCNG},{ }^{[65]}$ the dendritic regions showed a higher hardness than the interdendritic regions. 
During in-situ $\langle 1-1-0\rangle\{111\}$ micro-shear testing, one finds clear evidence for localized plastic deformation in the shear zones. Evidence is provided in the SEM micrograph of Figure 13. It was found that the stress drops that can be seen in the shear stress vs shear strain curves of Figure 12(b) are associated with sudden deformation events, which can either be the formation of a new shear band or a sudden strain burst in an existing shear band. Further work is required to study the in-situ micro-shear behavior of superalloy single crystals in more detail.

\section{SUMMARY AND CONCLUSIONS}

The objective of the present work is to show that shear testing of Ni-base superalloy single crystals at high and low temperatures represents a fascinating alternative to conventional tensile testing. From the results reviewed and reported in the present work, the following conclusions can be drawn:

(1) The Mayr double shear specimen allows to record reproducible shear creep data from all relevant temperature/stress regimes $\left(T: 750\right.$ to $1100{ }^{\circ} \mathrm{C}, \tau$ : 50 to $400 \mathrm{MPa})$. It has been and it is being used to study dislocation processes which govern creep. It has also contributed to a better understanding of rafting under multiaxial stress states.

(2) In the present work, stereo-transmission electron microscopy was used to produce 3D anaglyphs which allow the viewer to appreciate the spatial arrangement of creep dislocations in the $\gamma$-phase and in the $\gamma^{\prime}$-phase of a Ni-base single crystal superalloy. After macroscopic crystallographic $[01-1](011)$ shear creep testing in the high-temperature and low-stress creep regime, one finds that dislocation densities increase at $1050{ }^{\circ} \mathrm{C}$ with increasing stress and strain.

(3) Anisotropic 3D finite element creep stress calculations based on a constitutive model which was calibrated using uniaxial creep data from the low-temperature high-stress creep regime show that the shear zones of the major parts of the two shear zones in the Mayr double shear creep specimen are under a homogeneous shear stress state. This was previously only demonstrated using FEM creep stress calculations based on a simple Norton law which rationalized secondary creep data from the high-temperature and lowstress creep and assuming isotropic material behavior.

(4) In the low-temperature high-stress creep regime, the Mayr double shear creep test technique reveals a surprisingly strong crystallographic creep anisotropy, which strongly differs from the weak creep anisotropy which is observed at high temperatures and low stresses. The macroscopic crystallographic $[11-2](111)$ shear system deforms significantly faster than the $[01-1](111)$. This represents direct mechanical proof for the planar fault nucleation scenario which was proposed by Wu et al. ${ }^{[59]}$

(5) Based on the Mayr double shear specimen design, a micro-mechanical specimen for in-situ SEM shear testing has been designed. All critical dimensions are a factor of 1000 smaller. Using this specimen, one can show that a prior dendritic region (with lower $\gamma^{\prime}$ volume fraction of $72 \mathrm{pct}$ ) shows a lower critical resolved shear stress than a prior interdendritic region $\left(\gamma^{\prime}\right.$ volume fraction: 77 pct). During in-situ SEM shear deformation, one can directly observe the formation of localized shear bands in the two shear zones of the in-situ specimen.

\section{ACKNOWLEDGMENTS}

The present work resulted from a collaboration between SFB/TR 103 projects A1 (GE, KN, JS) and C4 (SG, AH). The SFB/TR 103 on Superalloy Single Crystals is funded by the Deutsche Forschungsgemeinschaft (DFG). LAJ from BAM acknowledges funding by the Deutsche Forschungsgemeinschaft (DFG) through the research Grant AG 191/1 and by the BAM Adolf Martens Fellowship Programme. AD from IPM-ASCR acknowledges financial support from CEITEC through Project MSMT LQ1601.

\section{OPEN ACCESS}

This article is distributed under the terms of the Creative Commons Attribution 4.0 International License (http://creativecommons.org/licenses/by/4.0/), which permits unrestricted use, distribution, and reproduction in any medium, provided you give appropriate credit to the original author(s) and the source, provide a link to the Creative Commons license, and indicate if changes were made.

\section{REFERENCES}

1. R.C. Reed: The Superalloys: Fundamentals and Applications, Cambridge University Press, Cambridge, 2006.

2. T.M. Pollock and S. Tin: J. Propul. Power, 2006, vol. 22, pp. 361-74.

3. A.B. Parsa, P. Wollgramm, H. Buck, C. Somsen, A. Kostka, I. Povstugar, P. Choi, D. Raabe, A. Dlouhy, J. Müller, E. Spiecker, K. Demtröder, J. Schreuer, K. Neuking, and G. Eggeler: Adv. Eng. Mater., 2015, vol. 17, pp. 216-30.

4. V. Yardley, I. Povstugar, P.P. Choi, D. Raabe, A.B. Parsa, A. Kostka, C. Somsen, A. Dlouhy, K. Neuking, E. George, and G. Eggeler: Adv. Eng. Mater., 2016, vol. 18, pp. 1556-67.

5. C. Mayr, G. Eggeler, G.A. Webster, and G. Peter: Mater. Sci. Eng. A, 1995, vol. 199, pp. 121-30.

6. American Society for Testing Materials, ASTM Special Publication No. 289, Symposium on Shear and Torsion Testing, ASTM, Philadelphia, 1961.

7. J.-P. Bardet: Experimental Soil Mechanics, Prentice Hall, New Jersey, 1997. 
8. A. Bertram, J. Olschewski, and M. Zelewski: Z. Angew. Math. Mech., 1991, vol. 71, pp. 387-90.

9. P.R. Parselay, C.H. Wells, G.R. Leverant, and L.H. Burck: $J$. Appl. Mech., 1971, vol. 104, pp. 623-26.

10. N. Ohno, T. Mizuno, H. Kawaji, and I. Okada: Acta Metall. Mater., 1992, vol. 40, pp. 559-67.

11. D. Nouhailhas and G. Cailletaud: Int. J. Plast., 1995, vol. 11, pp. $451-70$.

12. A. Matsuda: Trans. Jpn. Inst. Met., 1977, vol. 18, pp. 214-20.

13. W. Funk and E. Blank: Mater. Sci. Eng., 1984, vol. 67, pp. 1-11.

14. H. Raoult-Rogez: Thesis, Laboratoire de Thermodynamique et Physico-Chimie Métallurgiques (E.N.S.E.E.G.), Institut National Polytechnique, Grenoble, 1989.

15. D.M. Schwartz, J.B. Mitchell, and J.E. Dorn: Acta Metall., 1967, vol. 15 , pp. $485-90$.

16. F. Touratier, E. Andrieu, D. Pouquillon, and B. Viguier: Mater. Sci. Eng. A, 2009, vols. 510-511, pp. 244-49.

17. J. Henderson and J.D. Sneddon: J. Inst. Met., 1972, vol. 100, pp. $163-71$.

18. C. Roche: Thesis, Universite P. \& M. Curie, Paris, 1976.

19. U. von Alpen and J.C. Doukhan: Rev. Sci. Instrum., 1977, vol. 48, pp. $640-42$.

20. M. Arcan, Z. Hashin, and A. Voloshin: Exp. Mech., 1978, vol. 18, pp. $141-46$.

21. G. Peter, M. Probst-Hein, M. Kolbe, K. Neuking, and G. Eggeler: Materialwiss. Werkstofftech., 1997, vol. 28, pp. 457-64.

22. C. Mayr, G. Eggeler, and A. Dlouhy: Mater. Sci. Eng. A, 1996, vol. 207, pp. 51-63.

23. L.M. Pan, I. Scheibli, M.B. Henderson, and M. McLean: Asymmetric creep deformation of a single-crystal superalloy Acta Metall. Mater., 1995, vol. 43, pp. 1375-84.

24. L.M. Pan, B.A. Shollock, and M. McLean: P. R. Soc. A, 1997, vol. 453 , pp. $1689-1715$.

25. T. Kruml, J.L. Martin, B. Viguier, J. Bonneville, and P. Spätig: Mater. Sci. Eng. A, 1997, vol. 240, pp. 174-79.

26. M. Kolbe, A. Dlouhy, and G. Eggeler: Mater. Sci. Eng. A, 1998, vol. 246 , pp. 133-42.

27. G. Eggeler and A. Dlouhy: Acta Mater., 1997, vol. 45, pp. 4251-62.

28. R. Srinivasan, G. Eggeler, and M.J. Mills: Acta Mater., 2000, vol. 48 , pp. $4867-78$.

29. P.M. Sarosi, R. Srinivasan, G. Eggeler, M.V. Nathal, and M.J. Mills: Acta Mater., 2007, vol. 55, pp. 2509-18.

30. L. Agudo Jácome, P. Noertershaeuser, C. Somsen, A. Dlouhy, and G. Eggeler: Acta Mater., 2014, vol. 69, pp. 246-64.

31. A. Epishin and T. Link: Philos. Mag., 2004, vol. 84, pp. 1979-2000.

32. A. Kostka, G. Mälzer, G. Eggeler, A. Dlouhy, S. Reese, and T. Mack: J. Mater. Sci., 2007, vol. 42, pp. 3951-57.

33. C. Carry, S. Dermarkar, J.L. Strudel, and B.C. Wonsieicz: Metall. Mater. Trans. A, 1979, vol. 10A, pp. 855-60.

34. G.L. Drew, R.C. Reed, K. Kakehi, and C.M.F. Rae: in The Minerals, K.A. Green, ed., Metals and Materials Society, TMS, Warrendale, 2004, pp. 127-36.

35. M. Feller-Kniepmeier and T. Link: Metall. Mater. Trans. A, 1989, vol. 20A, pp. 1233-38.

36. R.D. Field, T.M. Pollock and W.H. Murphy: in Superalloys 1992, Proceedings of the 7th International Symposium of Superalloys, edited by: S.D. Antolovich et al., TMS, Warrendale, 1992, pp. 557-66.
37. R.R. Keller, H.J. Maier, and H. Mughrabi: Scr. Metall. Mater., 1993, vol. 28, pp. 23-28.

38. M. Feller-Kniepmeier, U. Hemmersmeier, T. Kuttner, and T. Link: Scr. Metall. Mater., 1994, vol. 30, pp. 1275-80.

39. L. Agudo Jácome, P. Noertershaeuser, J.K. Heyer, A. Lahni, J. Frenzel, A. Dlouhy, C. Somsen, and G. Eggeler: Acta Mater., 2013, vol. 61, pp. 2926-43.

40. O. Paris, M. Fahrmann, E. Fahrmann, T.M. Pollock, and P. Fratzl: Acta Mater., 1997, vol. 45, pp. 1085-97.

41. A. Epishin, T. Link, and G. Nolze: J. Microsc., 2007, vol. 228, pp. 110-17.

42. T. Link, A. Epishin, M. Paulisch, and T. May: Mater. Sci. Eng. A, 2011, vol. 528, pp. 6225-34.

43. V.A. Vorontsov, L. Kovarik, M.J. Mills, and C.M.F. Rae: Acta Mater., 2012, vol. 60, pp. 4866-78.

44. A.B. Parsa, P. Wollgramm, H. Buck, A. Kostka, C. Somsen, A. Dlouhy, and G. Eggeler: Acta Mater., 2015, vol. 90, pp. 105-17.

45. F. Louchet and M. Ignat: Acta Metall., 1986, vol. 34, pp. 1681-86.

46. R. Bonnet and A. Ati: Acta Metall., 1989, vol. 37, pp. 2153-69.

47. M.C. Carroll, K. Serin, and G. Eggeler: Mater. Sci. Eng. A, 2004, vol. 387 , pp. $590-94$.

48. M. Kamaraj, C. Mayr, M. Kolbe, and G. Eggeler: Scr. Metall. Mater., 1998, vol. 38, pp. 589-94.

49. K. Serin, G. Göbenli, and G. Eggeler: Mater. Sci. Eng. A, 2004, vols. 387-389, pp. 133-37.

50. M. Kamaraj, K. Serin, M. Kolbe, K. Neuking, and G. Eggeler: Materialwiss. Werkstofftech., 2003, vol. 34, pp. 469-77.

51. P. Wollgramm, H.K. Neuking, A. Parsa, S. Schuwalow, J. Rogal, R. Drautz, and G. Eggeler: Mater. Sci. Eng. A, 2015, vol. 628, pp. 382-95.

52. G. Eggeler: Mater. Sci. Technol., 2009, vol. 25, pp. 236-41.

53. http://www.sfb-transregio103.de, March 12th 2018.

54. L.A. Jácome, G. Göbenli, and G. Eggeler: J. Mater. Res., 2017, vol. 32, pp. 4491-4502.

55. L. Agudo Jácome, G. Eggeler, and A. Dlouhy: Adv. Scanning Transm. Electron Microsc. Struct. Funct. Eng. Mater. Ultramicrosc., 2012, vol. 122, pp. 48-59.

56. P. Caron, Y. Ohta, Y.G. Nakagawa, T. Khan: in Superalloys, S. Reichmann, et al., eds., The Metallurgical Society,TMS, Warrendale, 1988, pp. 215-24.

57. S. Gao, P. Wollgramm, G. Eggeler, A. Ma, J. Schreuer, and A. Hartmaier: Modell. Simul. Mater. Sci. Eng., 2018, vol. 26, p. 055001 .

58. P. Wollgramm, D. Bürger, A.B. Parsa, K. Neuking, and G. Eggeler: Mater. High Temp., 2016, vol. 33, pp. 346-60.

59. X. Wu, A. Dlouhy, Y.M. Eggeler, E. Spiecker, A. Kostka, C. Somsen, and G. Eggeler: Acta Mater., 2018, vol. 144, pp. 642-55.

60. C.M.F. Rae and R.C. Reed: Acta Mater., 2007, vol. 55, pp. $1067-81$.

61. J.K. Heyer, S. Brinckmann, J. Pfetzing-Micklich, and G. Eggeler: Acta Mater., 2014, vol. 62, pp. 225-38.

62. N. Wieczorek, G. Laplanche, J.K. Heyer, A.B. Parsa, J. PfetzingMicklich, and G. Eggeler: Acta Mater., 2016, vol. 113, pp. 32034.

63. E. Nembach: Particle strengthening of metals and alloys, Wiley, New York, 1997.

64. C. Tromas, M. Arnoux, and X. Milhet: Scripta Mater., 2012, vol. 66, pp. $77-80$.

65. P. Caron: in Superalloys 2000, T. Pollock, ed., TMS, Warrendale, 2000, pp. 737-64. 